\title{
Design of Dust Dispersion System for Explosion Chamber KV-150 M2
}

\author{
Richard Kuracina, and Zuzana Szabová
}

\begin{abstract}
Dust explosions are a major hazard in many industrial processes. In operations such as crushing and grinding, conveying, classifying and storage, an explosion may occur in the presence of combustible dusts or powders. Such explosions can result in loss of production, process equipment and quite possibly human life. This paper is oriented on design of dust dispersion system for explosion chamber KV-150 M2. The explosion chamber KV-150 M2 is designed to measure the explosion parameters of dispersed dusts.
\end{abstract}

Index Terms-Dust dispersion system; Dust Explosion; Explosion chamber; Fire protection.

\section{INTRODUCTION}

Many industrial accidents are imputable to explosions of flammable dusts. Protection from such accidental explosions requires the knowledge of flammability and explosion parameters of dust/air and/or dust-gas/air mixtures. Most of these parameters (minimum exposable concentration, MEC; limiting oxygen concentration, LOC; maximum explosion pressure, $\mathrm{p}_{\max }$; deflagration index, $\mathrm{KSt}$ ) are evaluated through standard tests performed in a closed steel combustion chamber with an internal volume of at least 20 $\mathrm{L}$, spherical or cylindrical (with a length to diameter ratio of approximately 1:1) in shape, according to standard procedures described in details in both European and American guidelines (the German Society of Engineers (VDI) Method 3673 (1995),the International Standards Organization (ISO) Method 6184/1, the American Society for Testing and Materials (ASTM) Method E 1226 2000) and the National Fire Protection Association (NFPA) Standard 68 (1994)) [1] One of the major requirements of the apparatus is that it must be capable of dispersing a fairly uniform dust cloud of the material [2].

The explosion is realised under the condition of space boundary, required concentration of the flammable material in the diffuse mixture with the possible oxidant and at the existence of the initiatory source [3].

Dust explosions in the process industries practically always start inside process equipment such as mills, dryers, mixers, classifiers, conveyors, and storage silos and hoppers. For any given dust type the ease with which dust clouds ignite and the rates with which they burn, vary considerably with factors well known in powder science and technology. The key factors include the primary particle size distribution of the dust, the degree of de-agglomeration of the dust

Published on December 12, 2018.

R. Kuracina is with Slovak University of Technology in Bratislava, Slovakia, (e-mail: richard.kuracina@stuba.sk)

Z. Szabová is with Slovak University of technology in Bratislava, Slovakia (e-mail: zuzana.szabova@stuba.sk). particles in the cloud, the dust concentration distribution in the cloud, and the cloud turbulence. The last three factors are entirely dependent on the actual process situation in which the dust cloud is generated and sustained [4].

To correctly manage dust cloud explosion risks [5], [6] the following are required:

1) Understanding of the explosion characteristics of the dust(s)

2) Identification of locations where combustible dust cloud atmospheres are or could be present during normal and abnormal operating conditions

3) Identification of potential ignition sources that could be present under normal and abnormal conditions

4) Proper process and facility design to prevent and/or minimize the occurrence of dust explosions and protect people and facilities against their consequences

5) Adequate maintenance of facilities to minimize ignition sources and dust releases [7].

\section{DUST DISPERSION SYSTEMS}

Nowadays, the dust dispersion systems are divided according to the deposition of the dust to be investigated into two principles:

- placing of dust directly at the nozzle,

- placing the dust in the reservoir outside the nozzle (splitting of) chamber and the nozzles (Fig. 1).

The first system works on the principle that the dust cloud is created by the nozzle. The air flow is led from the compressed air container to the bottom of the nozzle and it reflects on the dust sample. This causes raise the dust cloud inside the chamber.

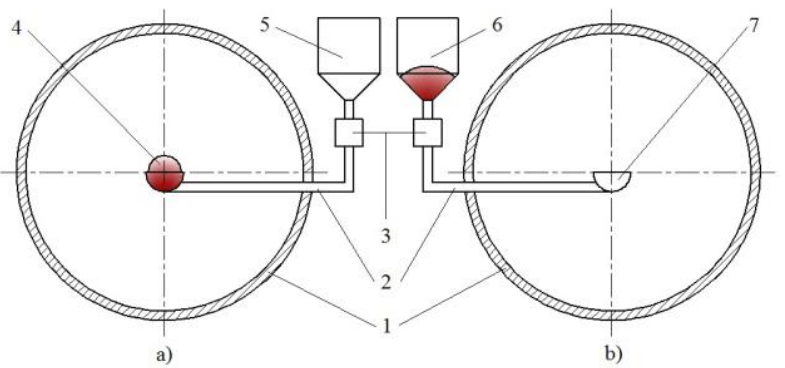

Fig. 1. dust dispersion systems: a) dust deposited immediately with the nozzle b) dust located outside the nozzle area: 1 - explosion chamber, 2 supply pipe, 3 - fast acting valve, 4 - nozzle with dust, 5 - compressed air reservoir, 6 -compressed air reservoir with the dust, 7 - nozzle

In the second system, the dust is located outside the nozzle and outside the chambers in the dust container. The dust particles are then entered by the pressurized air into the pipe and subsequently into the spray pipe. This create the 
dust cloud inside the chamber.

Dispersing in a 20-liter sphere is possible with the most dispersion devices, namely a perforated dispersion pipe (Fig. 4), the Rebound Nozzle (Fig. 5), and a Dahoe Nozzle (Fig. 2) [8].

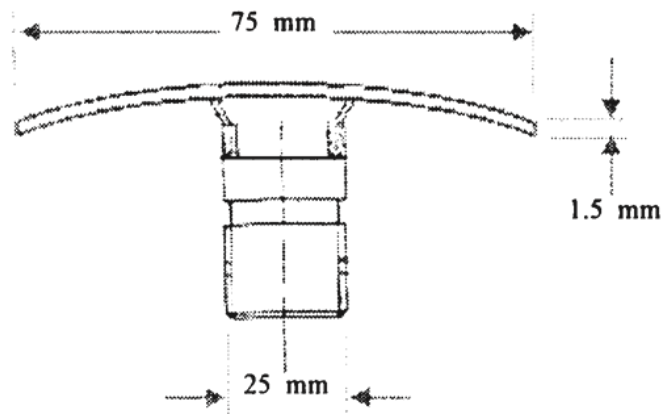

Fig. 2. Scheme of Dahoe Nozzle [9]

The measurement locations and the placement of the dust dispersion devices in the model sphere are shown in Fig. 3. The dispersing devices are connected to the compressed air container.

With the Rebound Nozzle (Fig. 5) and the Dahoe nozzle (Fig. 2), the dust can also be stored inside the chamber. It is poured around the nozzle, and the dispersing occurs when the compressed air enters the nozzle. However, the dust may also be deposited outside the chamber in the container and, similarly as with the tubular nozzle, injected into the interior of the chamber together with the compressed air [8].
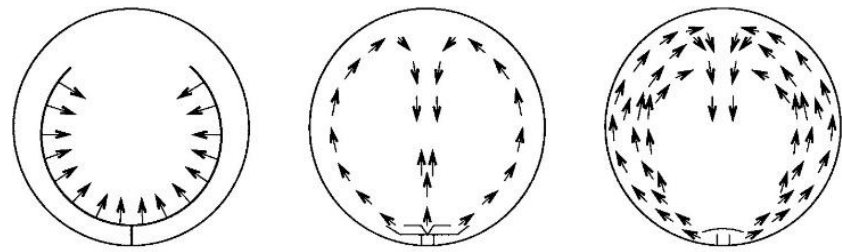

Fig. 3. Placement and initial flow patterns of the Perforated Dispersion Ring (left), Rebound Nozzle (middle) and the Dahoe Nozzle (right) [8]

There are several possible dispersion systems for explosion chambers. Standard STN EN 14034-1,2,3 + A1: 2011 Determination of explosion characteristics of dust clouds. Determination of the maximum explosion pressure $\mathrm{p}_{\max }$ of dust clouds prefers a dust dispersion system with a single dust and compressed air reservoir. A fast-acting valve is located at the bottom of the air reservoir. After opening the valve, the dust and the air are supplied to the disperser (nozzle). The disperser consists of a semi-circular perforated tube (inner diameter $21.7 \mathrm{~mm}$, diameter of holes $6 \mathrm{~mm}$ ) positioned concentrically with the wall of the explosion vessel, Fig. 4.

The standard also mentions the problematic dispersing when using this nozzle. This is a dust dispersing problem with larger particles and fiber samples.

This problem is also reported by Eckhoff [10]. There are also described deficiencies of the perforated dispersion tube after several experiments in the laboratories. The problem is mainly with fibrous dust, which is deposited inside the perforated tube and has not been sufficiently dispersed inside the chamber. This finding was undesirable and led to the development of an open system of nozzles under the name of a rebound nozzle. This nozzle gradually replaced the original perforated dispersion tube [10].

The standard describes a rebound nozzle (Fig. 5). It is a nozzle that reflects the air flow on the sample. Shape and dimensions are exactly set as shown Fig. 5. The standard also offers the use of a dispersion cup.
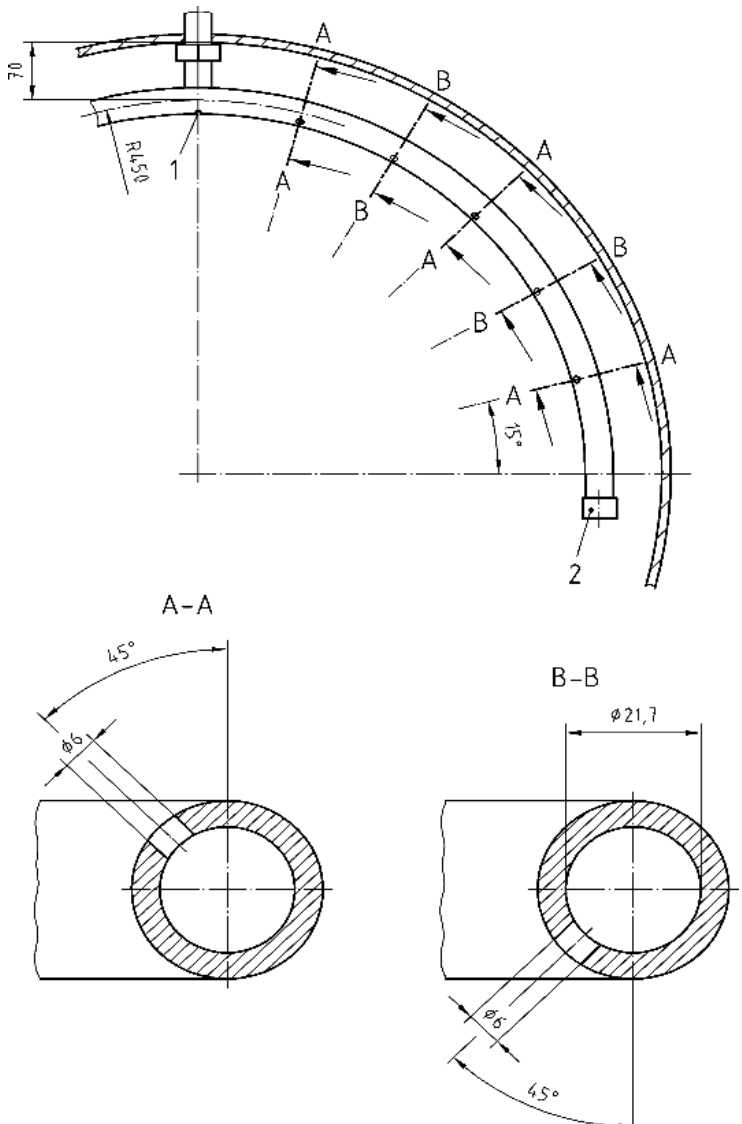

Fig. 4. Perforated semicircular spray pipe [11]

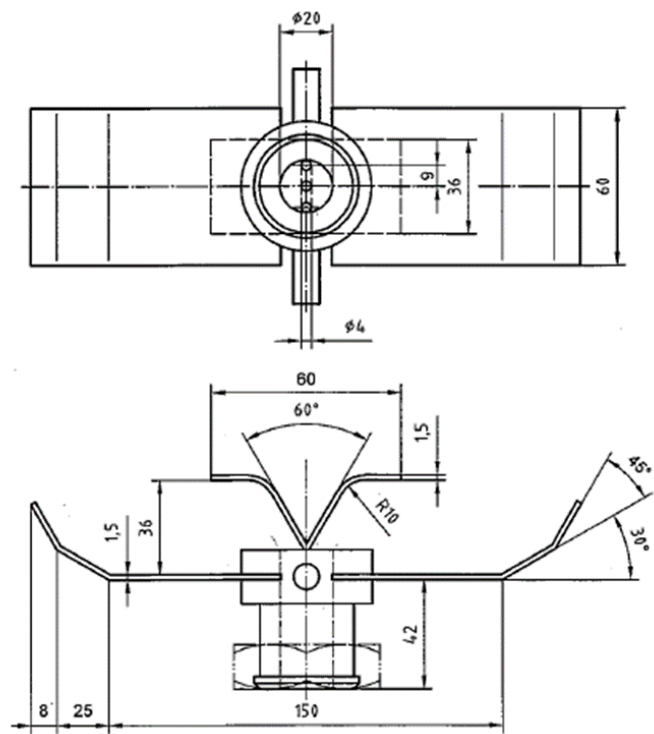

Fig. 5. Scheme of Rebound Nozzle [11]

For the 20-liter test sphere a modified dispersion system was developed in VSB Ostrava. This 20-liter test chamber is used to measure pressure, maximum rate of pressure rise, minimum initiation energy and minimum oxygen concentration. The system consists of a simple deflector above the dust sample (Fig. 6). Dust is located around the deflector. The compressed air is then reflected from the 
deflector and causes dispersing of dust [12].

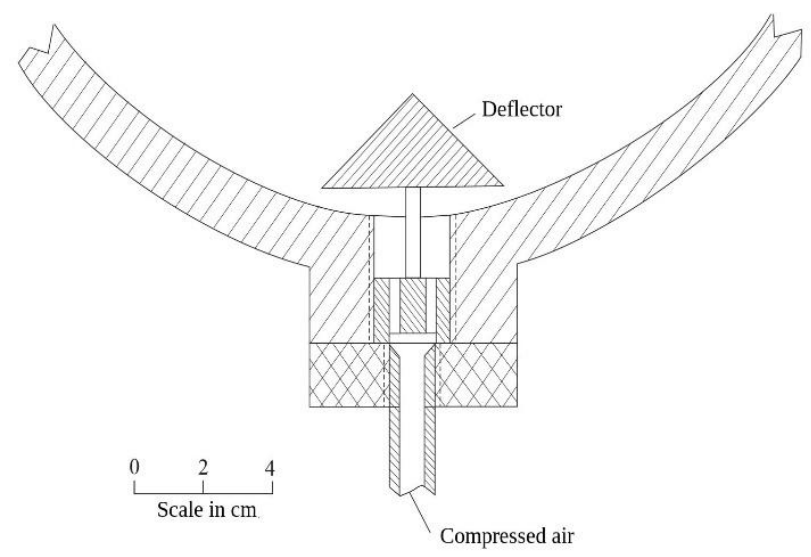

Fig. 6. Deflector disperser [12]

\section{DESIGN OF THE DUST DISPERSER FOR EXPLOSION CHAMBER KV-150 M2}

Due to the construction of the KV-150 M2 explosion chamber (position of transition windows), it is not possible to use a semicircular spray pipe for dispersion of dust samples. A normalized rebound nozzle (Fig. 5) can be used for dust dispersion in the chamber. In this case, a simple shape of pipeline can be used. The rebound nozzle would be located in position according to Fig. 8.

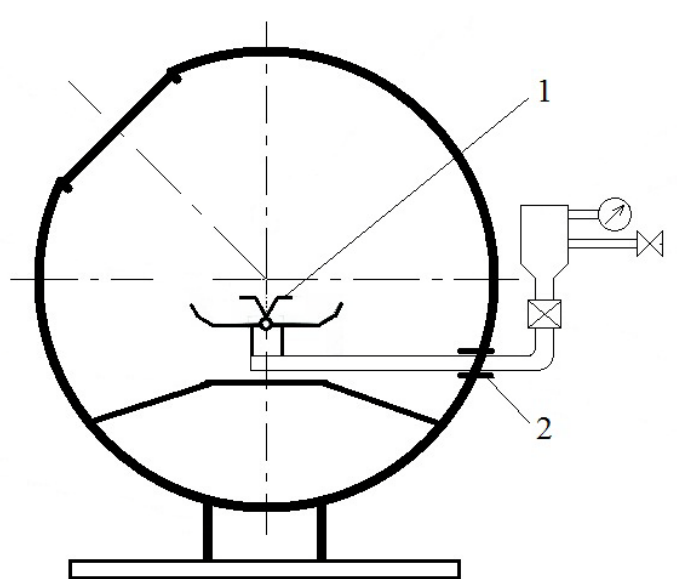

Fig. 7. The rebound nozzle placement in explosion chamber KV-150 M2 1 - the rebound nozzle, 2 - transition window

Compressed air release is controlled by fast acting valve.

Blasting cap activated valve (Fig. 8) is recommended by EN 14034. The valve has a mushroom-shaped seal. The seal is held in position against the pressure in the dust container by a small ring. The ring is destroyed by firing a blasting cap and the valve opens due to the pressure inside the dust container (see Fig. 2) [11].

An alternative type of fast acting valve for which conformity has been proven, is the Electro Pneumatic Valve. A valve with an electro pneumatic drive can be used instead of the fast acting valve. It shall be designed to withstand an internal overpressure of at least 20 bar. The opening time shall be $<100 \mathrm{~ms}$. For KV 150-M2 explosion chamber an electro pneumatic valve was chosen, Fig. 9

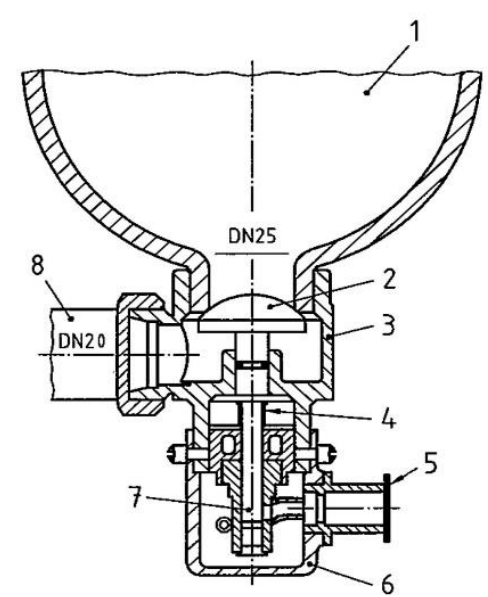

Fig. 8. Dust container with blasting cap activated valve (1 - dust container, 2 - mushroom shaped seal, 3 - seal housing, 4 - support ring, 5 - protective hood, 6 - protective hood, 7 - blasting cup, 8 - connecting tube) [11]

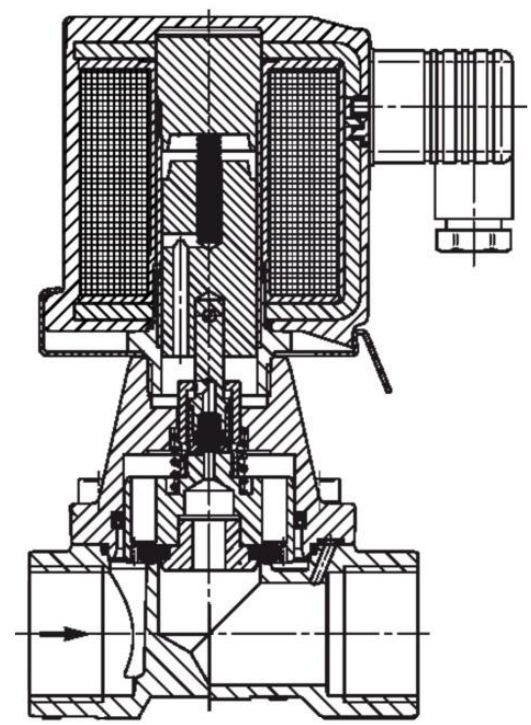

Fig. 9. Cross section of solenoid valve Norgren 85704 DN 25 [13]

The valve of this construction does not allow simultaneous use of the compressed air reservoir as a dust container. The airflow cannot transport particles of dust from the reservoir through the valve. The formation of the dust mixture is therefore possible only behind the valve. The solution is to use a dust container in the nozzle area.

The special dispersers were designed and constructed to disperse dust in the chamber (Fig. 11, 12). The nozzle is constructed from a pipe and a deflector. The deflector tube is screwed into the hole in the storage plate.

The design of the constructions are shown in Fig. 10. The nozzle is formed by a threaded pipe with the deflector. The deflector is formed by shaped sheet (obr. 11) or there is also possible to use hemispherical sheet (obr. 12). With the flow of compressed air to the deflector, turbulent airflow is generated to form dispersed dust cloud. The shape of the bowl ensures that the dispersed dust mixture is directed into the chamber. 


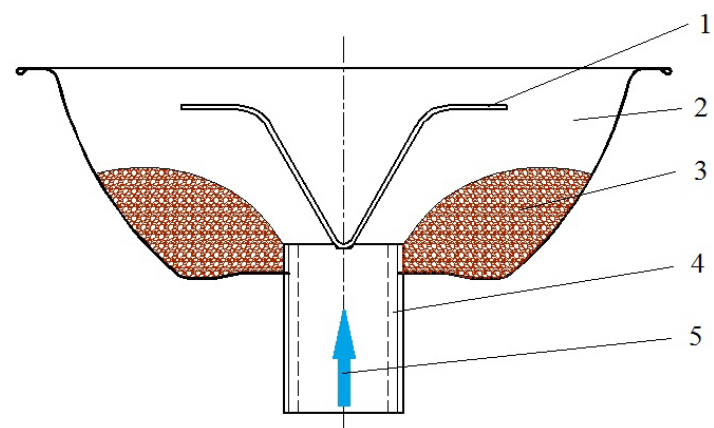

Fig. 10. Design of nozzle design for KV-150 M2 1 - Spin deflector, 2 Bowl, 3 - Test dust, 4 - Inlet thread, 5 - Direction of compressed air flow

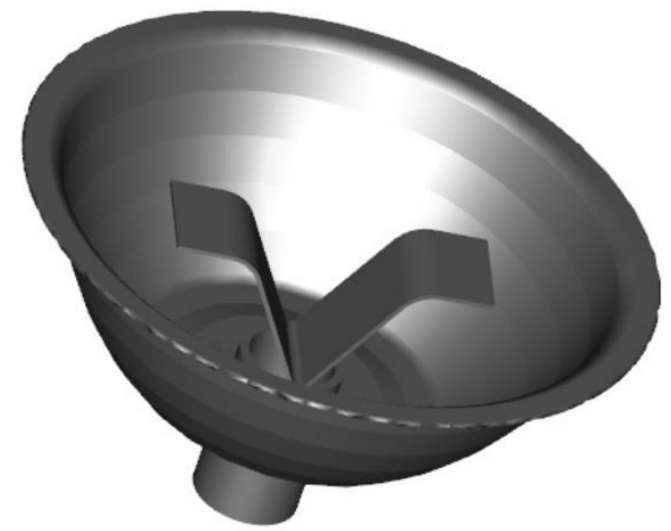

Fig. 11. Nozzle with shaped sheet deflector

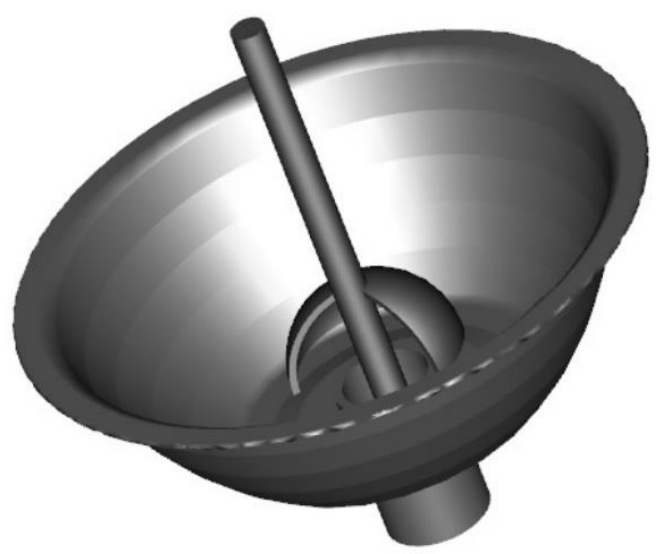

Fig. 12. Nozzle with hemispherical shape of deflector

\section{CONCLUSIONS}

The disperser is an important part of the explosion chamber. Several dust dispersers can be used for dust dispersing. Each dust disperser has its advantages and disadvantages. Based on the experience and the latest available scientific information, special dispersers for the KV 150-M2 explosion chamber have been developed. Production of this dispersers is economical and the operation is almost maintenance-free. On the basis of testing, it can be concluded that they meet the requirements of the standard. The dispersers eliminate the disadvantage of a standard dispersing system, which is the imperfect dispersing of the dust in the chamber.

In the future, the disperser design for the KV 150-M2 will be improved to achieve the optimal dust dispersion in the explosion chamber.

\section{ACKNOWLEDGMENT}

This research was supported by the Slovak Research and Development Agency under Contract No. APVV-16-0223, project VEGA 1/1010/16 and project 1610 20Lsphere.

\section{REFERENCES}

[1] Eckhoff R.K. "Differences and similarities of gas and dust explosions A critical evaluation of the European 'ATEX' directives in relation to dusts" Journal of Loss Prevention in the Process Industries, vol. 19, pp 553-560, 2006

[2] Sanchirico R., Di Sarli V., Russo P., Di Benedetto A. "Effect of the nozzle type on the integrity of dust particles in standard explosion tests", Powder Technology, vol 279, pp 203-208, 2015

[3] Vandlíčková M., Vraniak J. "Effect of the Particle Size of Wood Dust on Ignition Temperature", Key Engineering Materials, vol 775, pp 38 - 43, 2017

[4] Eckhoff R.K. "Understanding dust explosions. The role of powder science and technology", Journal of Loss Prevention in the Process Industries, vol. 22, pp 105-116, 2009

[5] Barton K. "Dust Explosion Prevention and Protection: A Practical Guide", Gulf Professional Publishing, p. 300, 2002

[6] Eckhoff R.K "Understanding dust explosions. The role of powder science and technology", KONA Powder and Particle Journal, vol 5 , Pages 54-67, 1997

[7] Vahid E. "Dust explosion hazard assessment" Journal of Loss Prevention in the Process Industries, vol. 23, pp 907-912, 2010

[8] Dahoe A.E., Cant R.S., Scarlett B. "On the Decay of Turbulence in the 20-Liter Explosion Sphere", Flow, Turbulence and Combustion, vol. 67, pp.159-184, 2001

[9] Mercer D.B., Amyotte P.R., Dupuis D.J., Pegg M.J., Dahoe A., de Heij W.B.C., Zevenbergen J.F., Scarlett B. "The influence of injector design on the decay of pre-ignition turbulence in a spherical explosion chamber", Journal of Loss Prevention in the Process Industries, vol. 14, pp 269 - 282, 2001

[10] Eckhoff R.K., "Dust explosion in the process industries", Gulf Professional Publishing, p. 754, 2003

[11] EN 14034-1+A1: 2011 Determination of explosion characteristics of dust clouds, 2011

[12] BEBČÁK A., SERAFÍN J., ADAMEC J., "Optimalization of the swirl process of industrial dusts", Transactions of the VSB - Technical University of Ostrava, Safety Engineering Series, Vol. 5 (1), p 1 - 10, 2010

[13] Pastier M. "Study of flammability of combustible organic dusts.", dissertation, Slovak University of Technology in Bratislava, p. 104 2014

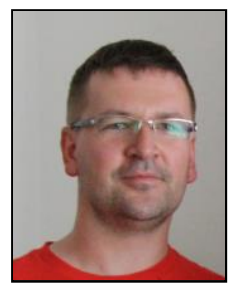

Richard Kuracina was born in Smolenice, Slovakia $\mathrm{He}$ has received her $\mathrm{PhD}$. in field of Theory and Technology of Explosives - University of Pardubice, Czechia. He is currently teacher at Faculty of Materials Science and Technology in Trnava, Department of Safety Engineering.

In the research he deals with risk assessment and study of the characteristics of flammable dusts, especially explosions. He has developed several patents that are used to investigate the measurement of dust explosion parameters. He is co-author of an innovative dispersing devices, igniters and control systems.

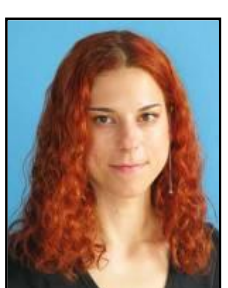

Zuzana Szabová was born in Bratislava, Slovakia. She has received her $\mathrm{PhD}$. in field of Mechanical Engineering and Materials - Slovak University of Technology in Bratislava, Faculty of Materials Science and Technology in Trnava. She is currently researcher at Faculty of Materials Science and Technology in Trnava, Department of Safety Engineering. Her research are OHS and safety engineering. 